\title{
Desobediencia civil, carácter moral y derecho. Una lectura de Michael
} Kohlhaas de Heinrich von Kleist*

\section{Civil disobedience, moral character and law. A reading of Michael Kohlhaas by Heinrich von Kleist}

\author{
Guillermo Lariguet ${ }^{* *}$ \\ *Este artículo de reflexión es posible gracias al apoyo de Conicet, Argentina y a los subsidios de investigación de la Secyt, Universidad \\ Nacional de Córdoba y a un proyecto PIP de Conicet, ambos referidos a la evaluación moral de instituciones públicas. \\ **PhD. en Derecho y Ciencias Sociales. Centro de Investigaciones Jurídicas y Sociales Universidad Nacional de Córdoba. gclariguet@ \\ gmail.com
}

Cómo citar: Lariguet, G. (2017) Desobediencia civil y carácter moral y derecho. Una lectura de Michael Kohlhaas de Heinnrich von Kleist. Inciso, 19(1): 72-81.

Recibido:07/10/2016 Revisado: 16/03/2017 Aceptado: 02/06/2017

\section{Resumen}

En este trabajo admito como axioma que la literatura es fuente de reflexión y enseñanza del Derecho. Al respecto, utilizo un relato literario de von Kleist, Michael Kohlhaas, para preguntarme por la relación -en la novela alemana- entre legitimidad de un gobierno y la acción de desobediencia civil. Además de ello, me pregunto acerca de cómo el carácter moral de un agente, en este caso Kohlhaas, puede conducirlo a una situación trágica.

Palabras clave: Literatura, legitimidad, desobediencia civil, carácter moral.
In this work I accept as an axiom that literature is a source of reflection and teaching of law. In this regard, I use a literary account of von Kleist, Michael Kohlhaas, to ask myself about the relationship - in the German novel - between the legitimacy of a government and the action of civil disobedience. In addition, I wonder how the moral character of an agent, in this case Kohlhaas, can lead to a tragic situation.

Key words: Literature, Legitimacy, Civil disobedience, Moral Character. 


\section{Introducción}

Por mor de la presente argumentación, aquí acepto como axioma que la literatura es una fuente indudable de reflexión y enseñanza del Derecho (Bonorino, 2011: 73-90). Pretendo articular una reflexión de tipo filosófico sobre una obra alemana. Concretamente, estoy pensando en Heinrich von Kleist (2006), escritor del período conocido como "romanticismo alemán" que, entre otras obras, escribió Michael Kohlhaas, una tragedia de dicho período ${ }^{1}$.

Se trata de una obra que pone en fricción al protagonista, Kohlhaas, un dueño de caballos, y el gobierno de su momento. Temáticas clásicas como el ejercicio del poder político, la corrupción, la aplicación del derecho, así como cuestiones acerca del carácter moral de Kohlhaas y otros personajes, los límites de la virtud, la afectación de la vida por planes oscuros de los otros, afloran aquí con toda nitidez.

Por lo anterior, creo que un buen ejercicio intelectual, puede ser desarrollar en este artículo el siguiente objetivo general, a saber: tomar con cierto detalle los temas planteados por Kohlhaas para reflexionar sobre un tema puntual en el que convergen la filosofía política y la filosofía del derecho, a saber: la desobediencia civil (Olmo Bau, 2000/2001:177-187).

El tema antes referido encuentra un punto axial de dificultad en la obra literaria de la que me ocuparé. Porque se trata de ver hasta dónde es justo castigar una desobediencia civil por un ejercicio injusto o corrupto del poder político. En la literatura teórica corriente, se suele asumir que la desobediencia civil aun si está moralmente justificada presupone que el agente desobediente acepte el castigo que el Estado le imponga. Ello debido a la propia justificación político-moral del Estado, llamada también "legitimidad". Como sostendré en este escrito, la legitimidad tiene

1. Se podría calificar de "tragedia" a tenor de lo explicado por Raymond Williams (2014) en Tragedias Modernas. En efecto, Kleist ofrece una reelaboración del género clásico atendiendo a preocupaciones sobre el poder político de su época. una doble fuente. O bien el "origen", porque el Estado o el "gobierno" surgen de una manera que la teoría política calificaría de legítimo. O bien, también por su ejercicio. Ambas características pueden concurrir en un caso, pero aun así son conceptualmente independientes. Un gobierno puede carecer de legitimidad de origen (por ejemplo, un gobierno de origen autocrático) pero ser un gobierno que luego se ejerza de manera sabia o justa. Al revés, un gobierno puede tener una noble cuna, pero su ejercicio ser injusto en una manera que revela una grave crisis moral en su pretensión de legitimidad. Esta es la segunda opción que, según creo, se puede asumir en Michael Kohlhaas.

Del lado del protagonista, sin embargo, también hay preguntas interesantes que formularse. Al parecer, Kohlhaas es el ejemplo de lo que podría denominarse un hombre "recto" y "noble". Empero, estas "virtudes" ¿no son las que lo conducirán a la desobediencia suya cuyo corolario será su inevitable muerte en manos del estado? Si la pregunta realizada cobra algún sentido, entonces debemos prestar atención a cómo Kleist describe los rasgos de carácter de este personaje (sobre carácter moral, Lariguet, 2014:221-249). Porque, a fin de cuentas, ¿qué esperamos que un hombre recto y noble haga en el caso de Kohlhaas?

Las dos preguntas antedichas, la que versa sobre la legitimidad del gobierno o estado, y la que versa sobre el carácter, serán las que tendrán centralidad en este trabajo. Para lo que considero ideas clave para destacar estos temas, me valdré del resaltado en cursiva en algunos párrafos significativos de la obra, tarea que acometeré en la sección 2. Para meterme de lleno en ambas cuestiones conceptuales, comenzaré en la referida sección por aislar partes pertinentes de la mentada obra literaria. Mi opinión es que con las herramientas teóricas sobre la legitimidad y la virtud, la desobediencia y el carácter, la obra habla por sí sola, pero el resaltado ayuda mejor 
a la visualización de los temas. En la sección 3 , repasaré la discusión jurídica que se libra en torno a la desobediencia del protagonista en el contexto de la obra. Finalmente, en la sección 4, y a modo de corolario, cerraré con una reflexión filosófica sobre las dos cuestiones ya indicadas líneas atrás: el carácter moral del protagonista y la naturaleza de su acto de desobediencia. Esto me permitirá concluir enfatizando en el carácter trágico de esta obra de von Kleist.

\section{El carácter de Kohlhaas y el origen de su tragedia}

“... hijo de maestro de escuela y uno de los hombres más rectos y a la vez más temibles de su tiempo" (von Kleist, 2006: 23), así comienza prácticamente su relato Kleist.

Según nuestro autor, Kohlhaas

"vivía plácidamente de su trabajo, educando a los hijos que su esposa le había dado en el temor de Dios y en el sentido del trabajo y la lealtad; no había entre sus vecinos quien no se hubiera complacido en su bondad y rectitud" (von Kleist, 2006: 23)

El destacado del autor en la rectitud y bondad de Kohlhaas hacen del protagonista el típico hombre de "nobleza de espíritu". Sin embargo, lo paradójico de su carácter moral, es que es el mismo, en conjunción con una situación externa del mundo consistente en una injusticia, tal como veremos, la que lo llevarán a torcer las ruedas de su vida. Así, Kleist afirma: "Más el sentido de justicia lo convirtió en bandido y asesino" (von Kleist, 2006: 23).

Todo comenzó un día que Kohlhaas pasaba con sus caballos por uno de los principados alemanes. Allí un oficial del príncipe, de mala manera, y de modo ladino, le dijo que no podía pasarlos sin pagar una especie de multa onerosa debido a que no llevaba unos "papeles especiales" que se requerían al efecto. Se trataba de una evidente mentira; mentira que hasta ese momento nuestro héroe no adivinaba. Concretamente el oficial, "mirándolo de través, le espetó el alcaide que sin permiso del Príncipe y sin las correspondientes credenciales no podían pasarse caballerías por la frontera". (von Kleist, 2006: 25)

Nuestro protagonista no mostró rebeldía frente a ese primer signo corrupto de un representante de la autoridad política. Al contrario,

Kohlhaas le aseguró que no era su intención faltar a las ordenanzas que pudiera haber sobre tráfico de caballos; le prometió que no dejaría de adquirir la credencial en la cancillería de Dresden, cuando pasara por la ciudad, y le pidió que por esta vez lo dejara marchar, puesto que nada había sabido de aquel requisito. (von Kleist, 2006: 28)

En palabras actuales, Kohlhaas está asegurando que cumplirá con la supuesta obligación y que si no lo ha hecho en el momento es porque desconocía esa norma; desconocimiento que una autoridad política sabia, en dichas materias, claramente no debería ni podría obviar.

Sin embargo, "no bien hubo llegado a Dresden... se enteró ... que la historia de las credenciales era pura invención". (von Kleist, 2006: 29) Pese a este descubrimiento, Kohlhaas aun persistía en su estado puro de nobleza originaria. No podía adivinar la oscura maleficencia que subyacía a esta historia; maleficencia que se debía al Príncipe que se había quedado con sus caballos. Así, esta moralidad de carácter que no permite ver el mal en los otros o la malevolencia, hace que Kleist afirme de Kohlhaas algo que sigue pintando algo significativo de su carácter moral. En efecto, "pero su sentido de la justicia, similar a la más fina balanza, no había dejado aún de oscilar; en el tribunal de sus adentros no se había probado aún que sobre su adversario pesase culpa", (von Kleist, 2006: 32) 
Como se verá luego, esta fina balanza de su sentido de justicia se inclinará hacia un extremo de desobediencia violenta. Pero de una desobediencia y, eso tenemos que averiguar aquí, respecto de la cual cabe determinar si tiene que tener por corolario sí o no el castigo para nuestro protagonista.

Su nobleza de carácter explica que,

Pese a las ofensas sufridas, le inclinara un sentimiento acertado experto en la frágil constitución del mundo, a sobrellevar la pérdida de los caballos como un desenlace legítimo de las cosas, si, como sostenía el alcaide, al criado -suyo-pudiera imputársele la más mínima culpa. (von Kleist, 2006: 33-34)

Veamos que Kleist nuevamente enfatiza en la idea de que Kohlhaas tiene un sentimiento acertado, propio de un virtuoso. Uno que además conoce que el mundo tiene una "constitución frágill", es decir, uno que conoce que la vida puede sufrir avatares devengados por la fortuna.

Nuestro protagonista no se quedó rumiando el enojo sino que apeló a los resortes habitualmente esperados en un estado de derecho. Dice Kleist:

Así, con la ayuda de un jurisconsulto conocido suyo, redactó una demanda, en la cual, tras una relación pormenorizada de los desmanes perpetrados por el Junker Wenzel von Tronka en su persona y en la de su criado Herse, reclamaba que se le castigara conforme a las leyes, que se le repusieran los caballos en su estado primitivo y que se les indemnizara por daños y perjuicios tanto a él como a su criado. La cuestión jurídica no admitía, en efecto, discusión. (von Kleist, 2006: 42)

El sentimiento acertado del mundo, la fina balanza, la rectitud, la bondad, la lealtad de Kohlhaas, sin embargo, fueron puestas a prueba de un modo que yo llamaría extraordinario. Dice Kleist: "Sin embargo, pasaron meses, y aun el año estuvo por vencer, antes de que de Sajonia le llegara siquiera una comunicación sobre el pleito que tenía entablado" (von Kleist, 2006. 43). Más aún:

Después de haberse dirigido repetidamente al tribunal, le preguntó en carta confidencial a su asesor por la razón de tan desmesurada demora; y se le dijo que, por insinuación superior, en la audiencia de Dresden habían arrumbado su querella". En respuesta a la perplejidad del tratante de caballos Kohlhaas, aquél le hizo saber que el Junker Wenzel von Tronka estaba emparentado con dos jóvenes señores, Hinz y Kunz de Tronka, el primero de los cuales era el copero del palacio, y el otro el mismo chambelán del soberano. (von Kleist, 2006 43)

Es decir, el "retardo excesivo de justicia", tal como Kleist nos lo hace saber, obedecía a corrupción, a nepotismo. El junker que se había quedado con sus caballos tenía familiares en el gobierno. Todo esto explicaba por qué una justa querella no era atendida. Debido a esto,

aquella noche le explicó su abogado que elevase al Príncipe Elector de Brandemburgo una súplica que contuviera una breve relación del caso, así como la carta del abogado de Dresden, y reclamase la protección del soberano, ante el atropello que con él, natural de Brandemburgo, se habían atrevido a cometer en territorio Sajón. Le prometió que llevaría el escrito a manos del Príncipe...y que éste, no dejaría de presentar su protesta ante el Elector de Sajonia. (von Keist, 2006: 45)

A su vez, "el Elector -de Sajonia- le había encargado que se ocupase de aquél asunto al conde Kallheim...que era familiar político de la casa Tronka". (von Kleist, 2006: 46) Es decir, nuevamente la "frágil constitución del mundo" hace que el caso caiga en un "familiar" del que había dañado a Kohlhaas. Ya era demasiado todo esto, se podría decir. No estábamos frente a un gobierno ejercido de manera justa sino 
corrupta. Los vejámenes a Kohlhaas no eran ordinarios sino ya extraordinarios, es decir, fuera de lo comúnmente esperable en un gobierno ejercido correctamente. Al advertir esta maraña de corrupción y malevolencia, Kleist afirma de nuestro protagonista: “...el dolor que le causaba contemplar el mundo en aquel infame desarreglo le sacudió el contento de poderse ver el pecho en el orden debido". (ibidem: 47-48) Kohlhaas dirá a su esposa: "Porque, querida Lisbeth, no deseo vivir en país donde no se me proteja en mis derechos" (von Kleist, 2006: 52) Es decir: al nepotismo, corrupción, malevolencia, se añade ahora un gobierno que no protege los derechos de Kohlhaas.

Todo lo vivido por el protagonista de esta historia, terminó causando tanto dolor en su esposa que esta murió. Kohlhaas había perdido mucho más que sus caballos. Ahora perdía a causa de todo esto a su esposa, nada menos. Había sido herido en sus derechos, en su auto estima, en su honra, en su buena fe, su bondad y rectitud habían sido injuriadas.

Pese a lo anterior, Kleist nos recuerda que su esposa, antes de morir, le leyó el versículo de la Biblia que reza: "perdona a tus enemigos; haz el bien a aquellos que te aborrecen". (von Kleist: 56) "Kohlhaas dijo para sí, empero: ¡Pues que Dios no me perdone nunca, si llega el día en que yo perdonase al Junker!

\section{La desobediencia de Kohlhaas y la discusión jurídica sobre su entidad}

Ante la ignominia del gobierno, Kohlhaas no pudo tolerar esta situación de injusticia. Decidió iniciar la invasión del castillo del Junker que le había quitado sus caballos y se había reído de él. Que había usado sus vínculos con el gobierno para evadir devolver los caballos e indemnizar a Kohlhaas.

Luego de invadir el castillo del Junker, nuestro protagonista "redactó el llamado Edicto kohlhaasiano que exhortaba a la población a denegar cualquier tipo de socorro al Junker Wenzel von Tronka, con quien él se hallaba en justa guerra". (ibídem: 62) "En otro edicto proclamado poco tiempo después se intitulaba señor exento de obligaciones con el mundo y con el Imperio y sometido únicamente a Dios". (ibídem: 65) Es decir, ahora era un señor que hoy diríamos está "fuera del estado de derecho", un señor que inicia la desobediencia al gobierno. En el edicto que proclamó se intitulaba

\section{[...] lugarteniente del arcángel San Miguel, que venía a castigar a sangre y a fuego la perfidia en que se había sumido el mundo... convocaba asimismo a todo el pueblo desde el castillo de Lützen, que había sorprendido y convertido en fortaleza, a que se le uniera y contribuyera así a instituir un nuevo orden de cosas. (von Kleist, 2006: 73)}

Kohlhaas, así, inicia lo que él asume como una "justa" guerra, es decir, como una desobediencia justificada por razones de tipo moral.

El caso de Kohlhaas adquirió tal magnitud que, recuerda Kleist, intervino nada menos que Lutero. Kleist lo rememora así: "En estas circunstancias, y respaldado por el prestigio que le otorgaba su posición en el mundo, asumió el doctor Martín Lutero la tarea de represar, con el poder de la palabra sosegada, a Kohlhaas dentro del dique del orden humano". (ibídem: 74) Lutero dijo:

Kohlhaas, tú que pretendes haber sido enviado para empuñar la espada de la justicia, ¿qué te arrogas tú, osado, cuando te sirves de la insanía de la ciega pasión, si de la coronilla al calcañar eres el colmo de la injusticia? (von Kleist: 75)

Prosigue Lutero diciéndole:

La espada que portas, sábelo, es la espada del crimen y de la vesania, eres un sedicioso y no un soldado de la justicia divina, $y$ tu fin en esta tierra no será otro que el potro y el 
patíbulo, y en el más allá, el infierno adonde se condenan el crimen y la impiedad. (von Kleist, 2006: 76)

En una palabra, Lutero subraya el hecho de que la espada no está justificada, no se la puede alzar contra el estado que goza de legitimidad. Pero, ¿cuál legitimidad? Es obvio que aquí el ejercicio del poder no ha sido legítimo contra Kohlhaas. Ello si es verdad lo que responde nuestro protagonista. Así, la respuesta de Kohlhaas a Lutero va en el sentido de que él ha sido repudiado en sus derechos. Afirma en forma contundente "Pero, desde que hay Estados, ¿cuándo se ha dado que nadie sea quien sea, se haya visto repudiado de su seno?" "...Es para mí aquel a quien se le deniega la asistencia de las leyes. Porque para que prospere mi trabajo necesito que me asistan las leyes". (von Kleist: 79)

En el contradictorio, chocan los argumentos de ambos personajes. Lutero advierte que el "pueblo" aprueba lo que hace Kohlhaas. Kleist lo recuerda: Según Lutero, "La opinión pública...había tomado partido por ese hombre, siendo el caso que incluso en Wittenberg, tres veces incendiada por él, se estaba unívocamente a favor suyo". (von Kleist: 85) Sin embargo, Lutero ensaya una doctrina jurídica para encarar el caso Kohlhaas. Advierte el carácter "extraordinario" del mismo. Y se percata de que Kohlhaas había sido puesto por el gobierno en una situación de estar casi en estado de naturaleza, es decir, "fuera de la ley civil". En este punto sostenía lo siguiente:

[...] en aquel extraordinario caso debía prescindirse del reparo de negociar con un ciudadano que hubiera tomado las armas; ya que, por el trato que se le había efectivamente dispensado, se le había colocado en cierto sentido fuera de la corporación estatal; y que, en resumidas cuentas, para salir de aquel apuro habría que considerarlo más como una fuerza extranjera que hubiera invadido el pais, interpretación con la que en cierta medida se acomodaba su condición de extranjero. (von Kleist: 85)

En el debate jurídico llevado a cabo por el gobierno acerca de qué hacer, las opiniones jurídicas eran variadas y tenían cierta sofisticación conceptual. Por ejemplo, el funcionario del Elector, Kunz, primo de Tronka, alegó que "ni las leyes divinas ni las humanas le daban al chalán facultad de tomarse venganza por su mano de la manera espeluznante que se había arrogado". (von Kleist: 86) El contrapunto a esta opinión no se hizo esperar. El gran canciller, el conde Wrede, le expuso al Elector "sus reservas respecto a la conveniencia de recurrir a los poderes del Estado en la ejecución de un correctivo notoriamente injusto con penetrante sensibilidad hacia la aquiescencia que sin cesar iba ganando el tratante en el país". Agregó que el modo de romper con las fechorias que se habian cometido contra Kohlhaas era mediante "la sola aplicación de la justicia, que permitiera reparar el acto sin contemplaciones la torpeza que se había cometido". (von Kleist, 2006: 87)

Requerido por el soberano, el príncipe Christiern von Meisen manifestó que "secundando el derecho de Kohlhaas, se estaba prescindiendo del extremo en que se verían restringidas las justas aspiraciones a reparación de Wittenberg, Leipzig, y el país entero que él había atropellado" (von Kleist, 2006: 87) Agregaba que "el orden del estado estaba tan desquiciado en todo cuanto atañera a aquel sujeto, que difícilmente podría recomponerse acudiendo a la ciencia del derecho en busca de principios". (von Kleist, 2006: 87) Es decir, el caso para Meisen era de tal gravedad y complejidad que el derecho no ofrecía una guía clara a través de principios que postulasen qué hacer frente al tema.

Como previa condición para el castigo de Kohlhaas el Príncipe von Meisen disponía que debía castigarse por su delito de ocultar la querella a Kunz, sólo así "el Estado recuperaría 
autoridad con que aplastar al tratante, cuya causa era notoriamente justa y a quien se le había puesto en las manos la espada que empuñaba". (von Kleist: 88) Dicho de otro modo: había que castigar primero a los corruptos del gobierno para "recuperar legitimidad" o, de lo contrario, el gobierno tendría las "manos sucias" para resolver con justicia el desafío a que había llevado la desobediencia violenta de Kohlhaas.

A lo anterior replicó el conde Kallheim sosteniendo que de esta manera nunca se saldaría el conjunto de maleficios producidos. Que por las mismas razones, y así se dirigió al Príncipe von Meisen, este "tendría que preocuparse igualmente de su sobrino, el Príncipe Friedrich: porque en la campaña extraordinaria contra Kohlhaas había transgredido las instrucciones que se le impartieron de atender el asunto del tratante de caballos". (von Kleist, 2006: 89)

Mientras el Elector, tras todas estas palabras, se acercaba indeciso a su mesa, terció en opinión el copero Hinz von Tronka (primo del Junker) alegando que no podía entender cómo la resolución correcta del asunto se les escapaba a todos de las manos. Que él supiera, "el compromiso del tratante era disolver su tropa a cambio de sólo un salvoconducto a Dresden y de la revisión de la causa. Pero de ahí no debía desprenderse, prosiguió, que se le hubiera de otorgar indulto". (von Kleist, 2006: 89)

El Príncipe Elector meditaba en que la salida más razonable era la propuesta por Wrede, esto es, la aplicación de la estricta justicia, devolviendo los caballos capturados por el Junker a Kohlhaas. El problema es que estos ya estaban para el desolladero y según Wrede, "conforme a derecho ya están muertos porque carecen de valor alguno y físicamente lo están antes de trasladarlos al desolladero". (von Kleist, 2006: 109) ¿Cómo hacer justicia entonces? Los caballos estaban en un estado tan macilento que ya no se podía cumplir con la reivindicación estrictamente solicitada en su querella por Kohlhaas. Él quería, recordemos, sus caballos tal como él los había entregado por la fuerza en su momento.

Luego de tanta discusión jurídica, se tomó la decisión de llevar a la horca a Michael Kohlhaas, antes de serle restituidos otros animales e indemnizado su criado. En un momento de la historia, sin embargo, una misteriosa gitana le dará un amuleto que vendrá a operar de "contra compensación" de nuestro protagonista contra la máxima autoridad que entenderá en su caso, el Elector de Sajonia. La gitana le dijo: en este amuleto que te doy están "el nombre del último soberano de tu casa, el año en que perderá su reino, y el nombre de quien lo arrebatará por la fuerza de las armas". (von Kleist, 2006: 150)

Ya a punto de morir en la horca Kohlhaas, el Príncipe refirió a la satisfacción obtenida por este (el valor de sus caballos cuando estos estaban en la plenitud de su vida, los desagravios del Junker, la reparación de perjuicios a él y su criado) y sostuvo "desagraviado de esta manera en el día de hoy, disponte tú a desagraviar por su parte a su Majestad imperial por haber quebrantado la paz territorial que él auspicia". ( von Kleist, 2006: 165)

Kohlhaas viendo al Elector antes de morir le mostró el relicario con la profecía de la gitana, mientras éste se retorcía de esperanza, y allí nomás se lo tragó, provocando el desplome del soberano" (von Kleist, 2006: 166)

\section{A modo de corolario: una reflexión moral sobre el carácter moral de Kohlhaas y sobre su desobediencia}

Como se ha podido apreciar, la obra de Kleist es una tragedia con el condimento necesario para ser reconocida como tal. Tiene un final funesto para su protagonista: la muerte no querida sino impuesta por el estado. Tal muerte es la respuesta estatal a un acto de desobediencia 
civil; acto público e "ilícito" (Gargarella, 2007: 1-29; Belloso Martín, 2013: 322-385), además de violento, ya que Kohlhaas inicia una "guerra" contra el Junker y luego contra otras poblaciones, con alto apoyo popular.

¿Cuáles son las causas de este desastre político, a la vez que moral? En primer lugar, una desafortunada secuencia de respuestas inmorales del estado a través de funcionarios corruptos y nepóticos. Este dato "externo" se hace patente en la frase del autor de esta obra cuando refiere a la "frágil constitución del mundo". En segundo lugar, es el propio carácter del protagonista, conformado por unas convicciones muy profundas, las que explican el desenlace fatal. Ambos ingredientes de lo que podríamos denominar el "canon de lo trágico" son reelaborados en esta etapa del romanticismo alemán.

Comencemos por el "carácter moral". Una y otra vez von Kleist destaca la "rectitud", "bondad", "lealtad" de Kohlhaas. Un hombre "temido", a la vez que un hombre poseedor de una "fina balanza" para enjuiciar moralmente los hechos de este mundo. La pregunta es, ahora, cómo un "virtuoso" como Kohlhaas puede "perder la virtud". ¿Acaso una característica del ser virtuoso no tiene que ver con la capacidad intrínseca de "retener" tal virtud, pese a las circunstancias adversas del mundo? Si la respuesta fuese afirmativa, se estaría admitiendo una teoría poderosa a la vez que muy exigente de virtud. No hay garantías de oro que permitan aseverar que el virtuoso siempre podrá serlo. Circunstancias "extraordinarias" como las experimentadas por Kohlhaas explicarían que su virtud no sea una salvaguarda. Pero, es que además, ¿un virtuoso debería quedarse cruzado de brazos ante la injusticia? La respuesta sería que no, que debería buscar "alternativas" ante los males que se le presentan. Sin embargo, no se podría refutar la afirmación de que Kohlhaas las buscó con afán. Inició todos los procesos legales, se inmiscuyó activamente en ellos, buscó un abogado que los llevara, inclusive sacrificó sus bienes en aras de su lucha legal.

No obstante los esfuerzos mencionados en pro de generar alternativas al mal, destinados a sostener que no siempre los males son "inevitables", la tragedia fue inescapable. Una línea de actos crueles, malévolos, injustos, de parte de los funcionarios corruptos del gobierno, que llevaron a desconocer su reclamo legal, condujeron al protagonista a la primera decisión de invadir el castillo del Junker, y luego a atacar otros puntos civiles.

En el discurso de Kohlhaas aparece la idea de que su vida experimenta una orfandad de un gobierno justo, de lo que hoy llamaríamos un "estado de derecho" "con todas las letras". Sus "derechos no son protegidos", dice él; más bien, han sido pisoteados. Esto se refuerza con la fina discusión doctrinal de los juristas del Príncipe que tienen que tomar una decisión acerca de cómo el gobierno debe responder al "crimen" de Kohlhaas. Varios de ellos admiten la "justificabilidad" del comportamiento de Kohlhaas, el hecho de que ha sido puesto casi en un "estado de naturaleza".

Por esto su caso es descrito como el de una fuerza "extranjera" invadiendo al territorio. Se entiende que su caso es "extraordinario" y que él ha sido puesto fuera de la "corporación estatal". Empero, el estado no quiere perder su fuerza, su capacidad de "castigo". El crimen de Kohlhaas no puede quedar impune o las bases del estado serían seriamente erosionadas. La cuestión es delicada puesto que Kohlhaas ha tenido gran concierto popular. Pero, por otra parte, como los propios juristas del príncipe advierten, el mismo estado se encuentra "sucio" para castigar. Pues, la corrupción nació allí en la maraña de corrupción de algunos funcionarios clave. Antes de castigar a Kohlhaas hay que castigar estos delitos de corrupción. Es la única manera, 
se dice en el texto, de que el estado "recupere legitimidad". Es como si la "ilegitimidad", en el sentido de mal ejercicio del poder, tuviese el posible poder deletéreo de envenenar también la legitimidad del estado qua origen.

Con lo antes esbozado, la pregunta filosófica es si Kohlhaas está moralmente justificado a hacer lo que hizo. Esta es una cuestión difícil de determinar. La doctrina filosófico-política es más o menos unánime en que la acción de Kohlhaas es un "delito" contra las bases venerables de legitimidad del estado (sobre la diferencia entre desobediencia civil y protesta social y antisistema, véase Seleme, 2013: 323-349).

El estado, "hegelianamente" hablando, tiene una presunción de legitimidad político-moral tras de sí. Es una forma superadora con la que el "espíritu objetivo" ha evolucionado. La carga de la prueba, por así decirlo, la tienen aquellos que intuyen que Kohlhaas sí está justificado moralmente. Pero, ¿cuál sería la base de apoyo de tal intuición? Sería que el estado goza de una legitimidad o pretensión de legitimidad eventualmente derrotable. Es decir, hay ocasiones en que tal legitimidad se quiebra por una serie de circunstancias; en este caso, como las circunstancias experimentadas por nuestro protagonista.

Entre estas circunstancias está el hecho de violar derechos, de dejar a alguien fuera de la protección estatal, como la protección de justicia. Decir lo contrario es afirmar que la legitimidad es absoluta. Si fuese absoluta, estaríamos dentro de lo que se conoce como el absolutismo estatal. Los juristas del caso se percatan de este problema. A tal punto es así que la solución del caso es de carácter "mixta". Se asume castigar a Kohlhaas para preservar el aura de legitimidad de "origen" del estado, minada por un ejercicio ilegítimo. Pero, a la vez, se "castiga" al autor de la desobediencia violenta. Kohlhaas no pudo vislumbrar entre las “alternativas" a la corrupción la protesta pacífica de Gandhi (Mingo Rodríguez, 2010: 62-75). Su respuesta es una respuesta romántica, violenta, impulsiva, donde los frenos inhibitorios dejan de operar.

Como sea, hay un problema sobre el que deseo llamar la atención y es el siguiente. Tal problema parte de admitir la "fricción" entre el discurso político de la legitimidad del estado y el discurso folk. Según el primero, no importa si el obrar del gobierno es malévolo e injusto. Kohlhaas debe ser castigado para mantener incólume la imagen venerable del estado, su aura de moralidad. Según la segunda, Kohlhaas no debería ser castigado. Su acto está moralmente justificado pues su lucha es signo de la falta de legitimidad pretendida del estado.

Creo que el problema formulado se puede reconstruir bajo la forma de un "dilema". Porque cualquiera de las dos opciones, la que enfatiza en la legitimidad del estado que debe preservarse, $o$ la que hace pie en la moralidad de la respuesta de Kohlhaas, llevan por senderos bifurcados. Empero, la intuición de que hay que alinear respuestas incompatibles conlleva la búsqueda de una "solución" de este dilema. La solución "óptima" consiste en escapar entre los cuernos del dilema, es decir, entre las dos alternativas que describí recién. Tal solución es compleja pues anuda dos dimensiones legales. Por una parte, se acepta jurídicamente que hay que "responder" a los reclamos de Kohlhaas, indemnizarlo a él y su criado de los daños sufridos tras la acción del Junker. Pero, por el otro, dado que la acción de nuestro protagonista fue ilegal, es necesario castigarlo en proporción a su crimen. Es decir, la existencia de intereses contrapuestos, es puesta en una balanza de compensaciones mutuas (sobre este tema Wallace, 1988: 86-87). Kohlhaas es compensado, aunque tristemente no pueda disfrutar de ello. Y el estado es compensado del hecho de que su legitimidad y fuerza hayan sido puestas en duda. Tal compensación, 
metafóricamente, se trasluce en el momento final. Mientras el príncipe carcomido por cuál será la verdad de la gitana sobre su "futuro" tirita de miedo, Kolhaas, antes de morir, y mirándolo fijo a los ojos, se traga el papelito con esa verdad. Kohlhaas muere, pero de algún modo el Príncipe también. Ambas potencias -morales si así se puede decir- se cancelan mutuamente.

\section{Referencias bibliográficas}

Belloso, N. (2013). La desobediencia civil y su polémica justificación. Revista direitos humanos e democracia. 1 (2), 328-385.

Bonorino, P. (2011). Sobre el uso de la literatura en la enseñanza del derecho, Málaga: REJIE. 4. 73-90.

Gargarella, R. (2007). El derecho de resistencia en situaciones de carencia extrema, Astrolabio. Revista internacional de filosofía.4, 322-385.

Kleist, von Heinrich. 2006. Micheal Kohlhaas. Presentación de Eustaquio Burjau. Traducción Javier Orduña. Madrid: Nórdica Libros.

Lariguet, G. (2014). Tragedia y Carácter Moral. En torno al saber del error. Filosofía y tragedia en Sófocles de Rocío Orsi. Discusiones, 14, 221-249.

Mingo, A. (2010). No violencia, desobediencia civil y ejemplaridad. Una aproximación al pensamiento ético-político de $\mathrm{M}$. Gandhi, Revista Paz y Conflicto. 3, 62-75.

Olmo, C. (2000/2001). Seguir pensando la desobediencia civil. Revista telemática de filosofía del derecho.4, 177-187.

Seleme, H. (2013). La protesta social como discurso político. En Rossetti, A. Álvarez M (ed) Derecho de huelga y protesta social. (323 - 349). Córdoba: Advocatus

Wallace, J. (1988). Moral relevance and moral conflict. Ithaca and London: Cornell University Press.

Williams, R. (2014). Tragedia moderna. Traducción y prólogo de Camila Arbuet. Barcelona: Osuna, Edhasa. 